\title{
Immunization knowledge and practice among Malaysian parents: a questionnaire development and pilot-testing
}

Ammar Ihsan Awadh ${ }^{1,2^{*}}$, Mohamed Azmi Hassali², Omer Qutaiba Al-lela ${ }^{3}$, Siti Halimah Bux', Ramadan M Elkalmi ${ }^{1}$ and Hazrina Hadi ${ }^{4}$

\begin{abstract}
Background: Parents are the main decision makers for their children vaccinations. This fact makes parents' immunization knowledge and practices as predictor factors for immunization uptake and timeliness. The aim of this pilot study was to develop a reliable and valid instrument in Malaysian language to measure immunization knowledge and practice (KP) of Malaysian parents.

Methods: A cross-sectional prospective pilot survey was conducted among 88 Malaysian parents who attended public health facilities that provide vaccinations. Translated immunization KP questionnaires (Bahasa Melayu version) were used. Descriptive statistics were applied, face and content validity were assessed, and internal consistency, test-retest reliability, and construct validity were determined.

Results: The mean \pm standard deviation (SD) of the knowledge scores was $7.36 \pm 2.29$ and for practice scores was $7.13 \pm 2.20$. Good internal consistency was found for knowledge and practice items (Cronbach's alpha $=0.757$ and 0.743 respectively); the test-retest reliability value was $0.740(p=0.014)$. A panel of three specialist pharmacists who are experts in this field judged the face and content validity of the final questionnaire. Parents with up-to-date immunized children had significantly better knowledge and practice scores than parents who did not $(p<0.001$ and $p=0.001$ respectively), suggesting a good construct validity. A significant difference was found in knowledge and practice scores among parents' age ( $p=0.006$ and $p=0.029$ respectively) and place of living $(p=0.037$ and $p=0.043)$. The parents' knowledge level was positively associated with their practice toward immunization (Spearman's rank correlation coefficient 0.310, $p=0.003$ ).
\end{abstract}

Conclusions: The pilot study concluded that the Bahasa Melayu version of the immunization KP questionnaire has good reliability and validity for measuring the knowledge and practices of Malaysian parents and therefore this version can be used in future research.

Keywords: Immunization, Reliability, Validity, Questionnaire development, Knowledge, Practice

\section{Background}

In health care, prevention of disease is always better than cure. It is undeniable that vaccines have been an important part in preventive medicine based on their successes in controlling vaccine-preventable diseases in the developed world. The eradication, elimination, and

\footnotetext{
* Correspondence: ammarehsan@yahoo.com

'Department of Pharmacy Practice, Kulliyyah of Pharmacy, International

Islamic University Malaysia, 25200 Kuantan, Malaysia

${ }^{2}$ Discipline of Social and Administrative Pharmacy, School of Pharmaceutical

Sciences, Universiti Sains Malaysia, 11800 Penang, Malaysia

Full list of author information is available at the end of the article
}

significant reduction in the number of cases of childhood communicable diseases as well as the fact that they extend life expectancy in the United States and many other parts of the world are some of the examples of immunizations' success in the 20th century [1].

Ehreth estimated that annually up to three million children's lives are saved by vaccinations, but still another three million lives worldwide are lost from vaccine-preventable diseases [2]. Furthermore, the advantages of vaccinations extend beyond just preventing specific diseases; they can prevent the development of 
antibiotic resistance, empower women, protect against bioterrorism, ensure safe travel and mobility, promote economic growth, enhance equity, promote peace, and extend life expectancy [3].

In Malaysia, immunization program was introduced in early 1950s and vaccines are provided free of charge in public health facilities nationwide. Impressive child immunization levels is one of the aspects that has contributed to Malaysian children's good health status [4]. Despite such global success and the proven impact on human health and life expectancy, vaccines are still under-utilized [5]. One hundred thirty million children are born annually, but around 30 million of them still have no access to vaccinations [2]. Low levels of compliance in a variety of settings have been clearly documented [6,7].

There are several factors that can lead to inadequate immunization. Studies have shown that improving parents' knowledge regarding vaccines improves immunization status and affects the success of immunization programs $[8,9]$. One of the major barriers towards children's immunizations is parental misperceptions toward immunizations [10]. Parents' misperceptions can lead to the suboptimal use of vaccines. In London, from 1996 to 2001, substantial measles outbreaks remained rare, occurring primarily because small clusters of parents had misguided safety concerns about vaccinations [11].

Because parents are the primary health decisionmakers for their children, their knowledge and practices regarding immunization in general have a great impact on the immunization status of their children [12,13]. The huge amount of conflicting vaccine-safety information and misinformation on the Internet can negatively influence parents' decisions [14]. Thus, there is a vital need to assess parents' knowledge and practice regarding their children immunization in order to improve and increase vaccination coverage and completeness.

Much has been published about parents' knowledge and practices regarding childhood immunizations [8,15-17]. However, no studies have been reported in Malaysia. This study was conducted to evaluate the knowledge and practices of Malaysian parents about their children's immunizations.

\section{Study objectives}

The main objectives of this study were to develop a questionnaire to measure immunization knowledge and practices (KP) among Malaysian parents, to translate the developed instrument into a Malay version, and to determine the validity and reliability of the developed translated instrument, and to assess differences in parents' KP across their socio-demographic characteristics. The questionnaire will help to identify the relationship between immunization KP of parents and the immunization status of their children.

\section{Methods}

\section{Development of the questionnaire}

The questionnaire was developed after an extensive literature search. The original questionnaire was developed in the English language in order to maintain consistency with the questions adapted from the references with and without modifications [1,5,18-21]. Additional questions were added to cover the objectives of this study. The final questionnaire consisted of 20 questions: 10 questions regarding knowledge with a "yes/no/don't know" answer format and 10 questions about practices with a "yes/no" answer format.

\section{Translation}

The questionnaire was translated into the Malaysian language (Bahasa Melayu) according to the recommended procedures and guidelines by Guillemin and Beaton $[22,23]$. In the first step, two different translators who speak both English and Bahasa Melayu, but whose native language was Bahasa Melayu, translated the questionnaire from English into Bahasa Melayu. In order to enhance the quality of the translation, one of the two translators was familiar with the aims of the questionnaire in this study whereas the other was not. One of the researchers, who is Malaysian-Malay, reviewed the two primary versions and compared them to the original; then, the first version of the questionnaire was prepared.

The second step involved the reverse translation of the questionnaire from the first version of the Bahasa Melayu questionnaire into English. The reverse translation was carried out by two other translators who were fluent in both English and Bahasa Melayu but who did not know the aims of this questionnaire. The result of the reverse translation was compared to the original English questionnaire, and the second report was prepared. Repeated discussions between all of the translators and the researchers were carried out in order to ensure the accuracy of the questionnaire.

The final stage was a pilot test of the questionnaire. Ten Malaysian parents completed the questionnaire and commented on the questions. These ten parents were not included in the study. Both the first report and the second report and the parents' comments were discussed by the researchers and necessary amendments were made accordingly. The final KP Questionnaire (Bahasa Melayu) version on immunization was done and made ready for the validity and reliability study.

\section{Data collection}

The data collection form consisted of two parts. The first part contained parents' socio-demographic data. The second part consisted of the knowledge and practice 
questionnaire (10 questions on knowledge and 10 questions on practice).

Parents who were visiting the clinic for any reason, had a child aged at least two years old (to ensure the completeness of immunization histories for the first two years of the child age), and not more than five years old, and lived in Pahang were included in this study. Parents who do not have a child aged at least two years old, and not more than five years old and, lived outside Pahang were excluded.

The data were collected from ten public clinics in five districts (Bera, Kuantan, Maran, Pekan, and Temerloh) across state of Pahang, the largest state in Peninsular Malaysia with an area of $36.173 \mathrm{~km}^{2}$ and population of 1,443,365 (2010 census). Eighty-eight Malaysian parents who attended public health facilities that provide vaccinations (a health clinic, a community clinic, and a maternal and child health clinic) were included in this study. For the pilot study, the recommended sample size was fewer than 100 subjects [24]. However, there were only 88 parents who fulfilled the study criteria.

Ethical approval for the study was obtained from the Medical Research Ethic Committee (MREC). All parents in the sample read a cover letter describing the study objectives and the time needed to fill in the questionnaire and received written informed consent for their participation before involving them in the research. The final translated version of the knowledge and practices questionnaire regarding childhood immunization was given to the parents.

\section{Validity and reliability study}

A panel of three specialist pharmacists who are experts in this field subsequently discussed and judged the face and content validity of the final questionnaire. The questions were modified as necessary to reflect the results of the pre-testing. To assess the reliability of the questionnaire, internal consistency reliability testing was conducted and test-retest reliability was conducted by asking a subgroup of these parents (12 parents) after a two-week period to complete a second copy of the questionnaire. A known-group validity technique was used to determine the construct validity of the questionnaire by assessing the association between parents' $\mathrm{KP}$ and the immunization status of their children (Up-to-Date and Not Up-to-Date).

\section{Statistical analysis}

The data were tabulated and analyzed using Microsoft Excel and the Statistical Package for Social Sciences SPSS 20 for Windows. The frequency and the percentage of each demographic data parameter, including age, gender, race, religion, number of pre-school children, family size, place of living, employment status, educational level, and family income were evaluated. The means and standard deviations were calculated for total knowledge score and total practice score, and they were treated as continuous variables. Scoring of the questions was determined by giving one point (1) for each correct answer and zero (0) for incorrect answers or for no response.

Mean and median for the total knowledge score and total practice score were calculated. The maximum possible score was 10 for each. Kruskal-Wallis and Mann- Whitney tests were used to determine the differences among groups for non-parametric distribution. Reliability was tested for internal consistency and corrected item-total correlations using Cronbach's alpha coefficient. Spearman's rank correlation coefficient was used to obtain test-retest reliability values [24]. Known group validity was assessed through the association of immunization status (Up-to-Date and Not Up-to-Date), total knowledge score, and total practice score by using the Mann-Whitney U test.

\section{Results}

\section{Characteristics of parents}

A total of 88 parents participated in this study. The vast majority of the respondent parents were mothers $92.0 \%$ $(n=81)$. The majority of the parents were between 20 and 40 years old $77.3 \%(n=68)$. The vast majority of the parents were Malay $76.1 \%(n=67)$. Most of the parents had a secondary education $68.2 \%(n=60)$ (Table 1$)$.

\section{Reliability \\ Internal consistency}

The mean \pm standard deviation for the total knowledge score and total practice score were $7.63 \pm 2.29$ and 7.13 \pm 2.20 , respectively. Internal consistency was determined for the 10 items of knowledge on the questionnaire and 10 items of practice on the questionnaire with Cronbach's value of 0.739 and 0.732 , respectively which indicate good reliability of both instruments.

The item-total correlations between the 10 items of knowledge on the questionnaire and 10 items of practice on the questionnaire are presented in Tables 2 and 3.

\section{Test-retest reliability}

The investigation for the test-retest reliability with an interval of two weeks for twelve parents showed satisfactory reliability and stability with a Spearman's rank correlation coefficient value of $0.740(p<0.05)$.

\section{Validity}

\section{Known-groups validity}

The Mann-Whitney U test showed a significant difference between parents' total knowledge score and their child immunization status, and between parents' total practice score and their child immunization status $(p<0.001$ and $p=0.001$ respectively). Parents who had 
Table 1 Socio-demographic characteristics of parents

\begin{tabular}{|c|c|c|}
\hline Parameters & Frequency $(n=88)$ & $\%$ \\
\hline \multicolumn{3}{|l|}{ Gender } \\
\hline Male & 7 & 8.0 \\
\hline Female & 81 & 92.0 \\
\hline \multicolumn{3}{|l|}{ Age } \\
\hline$<20$ & 5 & 5.7 \\
\hline $20-30$ & 36 & 40.9 \\
\hline $30-40$ & 32 & 36.4 \\
\hline$>40$ & 15 & 17.0 \\
\hline \multicolumn{3}{|l|}{ Race } \\
\hline Malay & 67 & 76.1 \\
\hline Chinese & 16 & 18.2 \\
\hline Indian & 3 & 3.4 \\
\hline Others & 2 & 2.3 \\
\hline \multicolumn{3}{|l|}{ Religion } \\
\hline Islam & 68 & 77.3 \\
\hline Buddhism & 16 & 18.2 \\
\hline Hinduism & 3 & 3.4 \\
\hline Others & 1 & 1.1 \\
\hline \multicolumn{3}{|c|}{ No. of preschool children } \\
\hline $1-2$ & 73 & 83 \\
\hline$>2$ & 15 & 17 \\
\hline \multicolumn{3}{|l|}{ Family size } \\
\hline$<4$ & 31 & 35.2 \\
\hline $4-6$ & 45 & 51.1 \\
\hline$>6$ & 12 & 13.6 \\
\hline \multicolumn{3}{|l|}{ Place of living } \\
\hline Rural & 38 & 43.2 \\
\hline Urban & 50 & 56.8 \\
\hline \multicolumn{3}{|l|}{ Employment status } \\
\hline Employed & 47 & 53.4 \\
\hline Unemployed & 41 & 46.6 \\
\hline \multicolumn{3}{|l|}{ Educational level } \\
\hline Primary & 7 & 8.0 \\
\hline Secondary & 60 & 68.2 \\
\hline Tertiary education & 21 & 23.9 \\
\hline \multicolumn{3}{|l|}{ Family income } \\
\hline$<$ RM 1000 & 19 & 21.6 \\
\hline RM1000-RM2000 & 27 & 30.7 \\
\hline RM2001-RM3000 & 19 & 21.6 \\
\hline RM3001-RM4000 & 10 & 11.4 \\
\hline$>$ RM4001 & 13 & 14.8 \\
\hline
\end{tabular}

up-to-date immunized children showed higher knowledge and practice scores than parents who did not (see Table 4).
Table $\mathbf{2}$ Reliability test of $\mathbf{1 0}$ items of the knowledge scale

\begin{tabular}{lll}
\hline Question no. & $\begin{array}{l}\text { Corrected item-total } \\
\text { correlation }\end{array}$ & $\begin{array}{l}\text { Cronbach's Alpha if } \\
\text { item deleted }\end{array}$ \\
\hline Q1 & 0.277 & 0.739 \\
Q2 & 0.570 & 0.698 \\
Q3 & 0.522 & 0.700 \\
Q4 & 0.385 & 0.720 \\
Q5 & 0.400 & 0.718 \\
Q6 & 0.336 & 0.729 \\
Q7 & 0.570 & 0.698 \\
Q8 & 0.255 & 0.743 \\
Q9 & 0.511 & 0.701 \\
Q10 & 0.316 & 0.729 \\
\hline
\end{tabular}

\section{Parents' knowledge and practice}

The parents' total knowledge score was positively associated with the total practice score toward immunization (Spearman's rank correlation coefficient 0.310, $p=0.003$ ).

A significant difference was found in the total knowledge scores and the total practice scores among parents' age groups ( $p=0.006$ and $p=0.029$ respectively) in that parents who were younger than 20 years old had lower knowledge and practice scores. A significant difference was also found in total knowledge scores and total practice scores among parents' place of living ( $p=0.037$ and $p=0.043$ respectively) in that parents who were living in urban areas had higher knowledge and practice scores. A significant difference was also found in total practice scores among parents' employment status $(p=0.037)$ in that employed parents showed higher practice scores (Table 5).

\section{Discussion}

The aim of this study was to develop a reliable and valid questionnaire covering all aspects of parents' immunization knowledge and practice that could be used in future studies to look at the relationship between Malaysian parents' immunization knowledge and practices and the immunization status of their children. This is the first time a questionnaire for measuring immunization knowledge and practices of Malaysian parents has been developed and validated.

Several instruments for measuring knowledge and practices regarding immunizations have been developed in various countries at different times $[20,21,25,26]$, using these instruments and/or comparing these studies can provide interesting results but must be done with caution. Indeed, because many factors can influence parents' knowledge, their attitudes and practices regarding immunization should be taken into account, such as their different socioeconomic characteristics, and the cultural and religious beliefs of different populations. 
Table 3 Reliability test of 10 items of the practice scale

\begin{tabular}{lll}
\hline Question no. & $\begin{array}{l}\text { Corrected item-total } \\
\text { correlation }\end{array}$ & $\begin{array}{l}\text { Cronbach's Alpha } \\
\text { if item deleted }\end{array}$ \\
\hline Q1 & 0.422 & 0.714 \\
Q2 & 0.413 & 0.707 \\
Q3 & 0.467 & 0.697 \\
Q4 & 0.454 & 0.700 \\
Q5 & 0.522 & 0.686 \\
Q6 & 0.384 & 0.712 \\
Q7 & 0.333 & 0.719 \\
Q8 & 0.317 & 0.726 \\
Q9 & 0.300 & 0.723 \\
Q10 & 0.394 & 0.715 \\
\hline
\end{tabular}

The developed questionnaire (in the English language) was translated into Bahasa Melayu, the common spoken language of Malaysians. The translation was carried out in accordance with the standard procedures detailed in translation guidelines by Beaton et al. [22] and Guillemin et al. [23]. The development and validation of the original items made the questionnaire relatively simple and practical to use among the Malaysian population.

The internal consistency reliability of the final questionnaire was good for both knowledge and practice (exceeded the minimum $\alpha$-coefficient of 0.70). The testretest reliability was also good. The known group validity showed parents of children who had up-to-date immunizations had significantly higher knowledge and practice scores than those who did not. This significant difference between the scores (total knowledge score/total practice score) of the parents who had up-to-date immunized children and those who did not, indicates that the questionnaire had a good construct validity.

The finding of the study indicates that the developed, translated questionnaire truly measures the immunization knowledge and practice of Malaysian parents. Moreover, the finding indicates how parents' knowledge and practice can affect the immunization status of their children.

This study found significant positive correlations between parents' knowledge level and their practice level; this is consistent with other studies conducted in China and in Iraq $[21,26]$. This shows that parents who have adequate levels of knowledge regarding immunization also have positive practices towards immunization.
This study found significant differences in knowledge and practice scores of the parents of different age groups. Parents who were younger than 20 years old showed significantly lower knowledge and practice scores than older parents. This result is consistent with other studies that found older parents to have better knowledge and practice $[27,28]$. This might be because older parents have more life experiences and better education.

This study also found that the parents' place of living was correlated with a significant difference in the knowledge and practice scores. Parents who were living in urban areas had better knowledge and practice scores. Many studies have found that rural areas in developing countries have lower immunization coverage and ageappropriate immunization rates due to rural-urban inequities [29-31]. A significant difference between practice scores and employment status was also found. Employed parents had better practice score than unemployed parents. However, the result showed no significant differences in other demographic parameters, such as gender, race, religion, number of pre-school children, family size, educational level, or family income.

Health care professionals must be aware of parents' knowledge and awareness of their children's immunization to be able to design effective public education programs or measures that can help parents to make the right decisions about their children's health and wellbeing. Those with inadequate knowledge and practices regarding immunization need to be targeted to maintain and improve immunization coverage.

\section{Limitations}

The sample of parents was obtained from the state of Pahang (the largest state in Peninsular Malaysia) where the study was conducted, and the sample was smaller than samples used in previous studies. The findings of this pilot study may not reflect the knowledge and practice of all Malaysian parents; rather they reflect only the knowledge and practice of those who actually included in the study. Therefore, the findings need to be interpreted within the context of study limitations.

\section{Conclusions}

This pilot study found the developed knowledge and practice questionnaire is a valid and reliable instrument for measuring Malaysian parents' immunization knowledge

Table 4 Relationship between knowledge scores and practice score and immunization status

\begin{tabular}{|c|c|c|c|c|c|c|}
\hline Parameter & $\begin{array}{l}\text { Knowledge scores } \\
\text { mean }\end{array}$ & $\begin{array}{l}\text { Knowledge scores } \\
\text { median }\end{array}$ & $P$ Value & Practice scores mean & Practice scores median & $P$ Value \\
\hline Immunization status & & & $<0.001^{*}$ & & & $0.001^{*}$ \\
\hline Up to Date & 8.14 & 9.00 & & 7.62 & 8.00 & \\
\hline Not Up to Date & 6.09 & 6.50 & & 5.64 & 6.50 & \\
\hline
\end{tabular}

*Significant, $P$-value $<0.05$. 
Table 5 KP score difference between different demographic parameters

\begin{tabular}{clc}
\hline Parameter & $\begin{array}{l}\text { Knowledge scores } \\
\text { mean }\end{array}$ & $\begin{array}{l}\text { Knowledg } \\
\text { median }\end{array}$ \\
\hline Gender & & \\
Male & 9.00 & 9.00 \\
Female & 7.51 & 8.00 \\
Age & & \\
$<20$ & 5.00 & 5.00 \\
$20-30$ & 7.33 & 8.00 \\
$30-40$ & 7.94 & 9.00 \\
$>40$ & 8.53 & 9.00
\end{tabular}

Race

$\begin{array}{ll}\text { Malay } & 7.84 \\ \text { Chinese } & 7.63 \\ \text { Indian } & 4.00 \\ \text { Others } & 6.00 \\ \text { Religion } & \end{array}$

9.00

8.00

3.00

6.00

Religion

$\begin{array}{ll}\text { Islam } & 7.84 \\ \text { Buddhism } & 7.63 \\ \text { Hinduism } & 4.00 \\ \text { Others } & 4.00\end{array}$

No. of preschool children

$\begin{array}{ll}1-2 & 7.59 \\ 3-4 & 7.80\end{array}$

Family size

$\begin{array}{ll}<4 & 7.61 \\ 4-6 & 7.69 \\ >6 & 7.42\end{array}$

Place of living

$\begin{array}{ll}\text { Rural } & 7.24 \\ \text { Urban } & 8.13\end{array}$

Employment status

$\begin{array}{ll}\text { Employed } & 7.98 \\ \text { Unemployed } & 7.22\end{array}$

Educational level

$\begin{array}{lll}\text { Primary } & 7.86 & 9.00 \\ \text { Secondary } & 7.53 & 8.00 \\ \text { Tertiary } & 7.6250 & 8.00\end{array}$

Family income

$\begin{array}{lll}<\text { RM 1000 } & 7.11 & 7.00 \\ \text { RM1001-RM2000 } & 7.74 & 8.00 \\ \text { RM2001-RM3000 } & 8.11 & 8.00 \\ \text { RM3001-RM4000 } & 7.50 & 8.50 \\ >\text { RM4001 } & 7.54 & 9.00\end{array}$

*Significant, $p$-value $<0.05$.

8.00

3.00

4.00

8.00

9.00

8.00

8.00

8.50

8.00

9.00

9.00

8.00

\begin{tabular}{llll}
$\begin{array}{l}\boldsymbol{P} \\
\text { value }\end{array}$ & $\begin{array}{l}\text { Practice scores } \\
\text { mean }\end{array}$ & $\begin{array}{l}\text { Practice scores } \\
\text { median }\end{array}$ & $\begin{array}{l}\boldsymbol{P} \\
\text { value }\end{array}$ \\
\hline 0.095 & & & 0.505 \\
& 7.86 & 7.00 & \\
& 7.06 & 7.00 &
\end{tabular}

$0.006^{*}$

$0.029^{*}$

7.00

7.00

7.00

9.00

0.093

0.461

$\begin{array}{ll}7.13 & 7.00 \\ 7.50 & 7.00 \\ 4.67 & 3.00 \\ 7.50 & 7.50\end{array}$

0.067

0.286

\subsection{8}

7.00

7.50

7.00

4.67

3.00

5.00

5.00

0.791

$6.92 \quad 7.00$

$8.13 \quad 8.00$

0.988

0.632

$7.42 \quad 8.00$

$6.93 \quad 7.00$

$\begin{array}{ll}7.08 & 7.00\end{array}$

$0.037^{*}$

$0.043^{*}$

$6.66 \quad 7.00$

$7.48 \quad 8.00$

0.140

$0.031^{*}$

$7.62 \quad 8.00$
6.56

$\begin{array}{ll}6.56 & 7.00\end{array}$

0.611

$6.00 \quad 7.00$

$\begin{array}{ll}7.18 & 7.00\end{array}$

$7.3333 \quad 8.00$

0.844

0.567

$\begin{array}{ll}6.79 & 7.00 \\ 7.19 & 7.00 \\ 7.74 & 8.00 \\ 6.70 & 7.00 \\ 6.92 & 8.00\end{array}$


and practices. This questionnaire should provide a useful tool in research on immunization knowledge and practice and allow for better understanding of the relationship between Malaysian parents' knowledge and practices and the immunization status of their children.

\section{Competing interests}

The authors declare that they have no competing interests.

\section{Authors' contributions}

This paper is a part of AA PhD. The research was conducted by AA and supervised by $\mathrm{MH}, \mathrm{OA}$, and $\mathrm{HB}$. The research project was designed by $\mathrm{AA}$, $\mathrm{AH}$, and $\mathrm{OA}$. The ethical approval was obtained by $\mathrm{AA}$, and HB. AA, OA, and $\mathrm{HH}$ developed and validated the questionnaire. Data collection was done by AA. RE contributed in the statistical analysis and $\mathrm{HH}$ helped in drafting the manuscript. All authors read and approved the final manuscript.

\section{Acknowledgements}

The authors would like to thanks the medical officers in charge and the nurses in the clinics for their support in this study and also the parents who agreed to participate in this study.

\section{Author details}

${ }^{1}$ Department of Pharmacy Practice, Kulliyyah of Pharmacy, International Islamic University Malaysia, 25200 Kuantan, Malaysia. ${ }^{2}$ Discipline of Social and Administrative Pharmacy, School of Pharmaceutical Sciences, Universiti Sains Malaysia, 11800 Penang, Malaysia. ${ }^{3}$ School of Pharmacy, Faculty of Medical sciences, University of Duhok (UOD), Duhok, Iraq. ${ }^{4}$ Department of Pharmaceutical Technology, Kulliyyah of Pharmacy, International Islamic University Malaysia, 25200 Kuantan, Malaysia.

Received: 9 July 2014 Accepted: 21 October 2014

Published: 27 October 2014

\section{References}

1. Gellin BG, Maibach EW, Marcuse EK: Do parents understand immunizations? A national telephone survey. Pediatrics 2000, 106(5):1097-1102.

2. Ehreth J: The global value of vaccination. Vaccine 2003, 21(7):596-600.

3. Andre F, Booy R, Bock H, Clemens J, Datta S, John T, Lee B, Lolekha S, Peltola H, Ruff T: Vaccination greatly reduces disease, disability, death and inequity worldwide. Bull World Health Organ 2008, 86(2):140-146.

4. WHO: Country cooperation strategy at a glance: Malaysia. 2013.

5. Pelly L, MacDougall DP, Halperin B, Strang R, Bowles S, Baxendale D, McNeil S: THE VAXED PROJECT: An assessment of immunization education in Canadian health professional programs. BMC Med EduC 2010, 10(1):86.

6. Gust DA, Strine TW, Maurice E, Smith P, Yusuf H, Wilkinson M, Battaglia M, Wright R, Schwartz B: Underimmunization among children: effects of vaccine safety concerns on immunization status. Pediatrics 2004, 114(1):e16-e22.

7. Skull SA, Andrews RM, Byrnes GB, Kelly HA, Nolan TM, Brown GV, Campbell DA: Missed opportunities to vaccinate a cohort of hospitalised elderly with pneumococcal and influenza vaccines. Vaccine 2007, 25(28):5146-5154.

8. Anjum Q, Omair A, Inam S, Ahmed Y, Usman Y, Shaikh S: Improving vaccination status of children under five through health education. J Pak Med Assoc 2004, 54(12):610.

9. Suarez $L$, Simpson DM, Smith DR: The impact of public assistance factors on the immunization levels of children younger than 2 years. Am J Public Health 1997, 87(5):845-848.

10. Heininger U: An internet-based survey on parental attitudes towards immunization. Vaccine 2006, 24(37):6351-6355.

11. Atkinson P, Cullinan C, Jones J, Fraser G, Maguire H: Large outbreak of measles in London: reversal of health inequalities. Arch Dis Child 2005, 90(4):424-425

12. Szilagyi PG, Hager J, Roghmann KJ, Doane C, Cove L, Rodewald LE, Humiston SG, Fleming GV, Hall CB: Immunization practices of pediatricians and family physicians in the United States. Pediatrics 1994, 94(4):517-523.

13. Orenstein WA, Atkinson W, Mason D, Bernier RH: Barriers to vaccinating preschool children. J Health Care Poor Underserved 1990, 1(3):315-330.

14. Zimmerman RK, Wolfe RM, Fox DE, Fox JR, Nowalk MP, Troy JA, Sharp LK. Vaccine criticism on the World Wide Web. J Med Internet Res 2005, 7(2):e17.
15. Adhikari P, Dhungel $S$, Shrestha $R$, Khanal $S$ : Knowledge attitude and practice (KAP) study regarding facts for life. Nepal Med Coll J 2006, 8(2):93.

16. Impicciatore P, Bosetti C, Schiavio S, Pandolfini C, Bonati M: Mothers as active partners in the prevention of childhood diseases: maternal factors related to immunization status of preschool children in Italy. Prev Med 2000, 31(1):49-55.

17. Shah B, Sharma M, Vani S: Knowledge, attitude and practice of immunization in an urban educated population. Indian J Pediatr 1991, 58(5):691-695.

18. Prislin R, Dyer JA, Blakely CH, Johnson CD: Immunization status and sociodemographic characteristics: the mediating role of beliefs, attitudes, and perceived control. Am J Public Health 1998, 88(12):1821-1826.

19. Mollema L, Wijers N, Hahné SJ, van der Klis FR, Boshuizen HC, de Melker HE: Participation in and attitude towards the national immunization program in the Netherlands: data from population-based questionnaires. BMC Public Health 2012, 12(1):57.

20. Qidwai W, Ali SS, Ayub S: Knowledge, attitude and practice regarding immunization among family practice patients. J Dow Uni Health Sci 2007, 1(1):15-19.

21. Al-lela OQB, Bahari MB, Al-abbassi MG, Basher AY: Development of a questionnaire on knowledge, attitude and practice about immunization among Iraqi parents. J Public Health 2011, 19(6):497-503.

22. Beaton DE, Bombardier C, Guillemin F, Ferraz MB: Guidelines for the process of cross-cultural adaptation of self-report measures. Spine 2000 25(24):3186-3191.

23. Guillemin F, Bombardier C, Beaton D: Cross-cultural adaptation of health-related quality of life measures: literature review and proposed guidelines. J Clin Epidemiol 1993, 46(12):1417-1432.

24. Rattray J, Jones MC: Essential elements of questionnaire design and development. J Clin Nurs 2007, 16(2):234-243.

25. Pavia M, Rita Foresta M, Carbone V, Angelillo IF: Influenza and pneumococcal immunization in the elderly: knowledge, attitudes, and practices among general practitioners in Italy. Public Health 2003, 117(3):202-207.

26. Zhang $X$, Wang $L$, Zhu $X$, Wang $K$ : Knowledge, attitude and practice survey on immunization service delivery in Guangxi and Gansu, China. Soc Sci Med 1999, 49(8):1125-1127.

27. Al-lela OQ, Bahari MB, Salih MR, Al-abbassi MG, Elkalmi RM, Jamshed SQ: Factors underlying inadequate parents' awareness regarding pediatrics immunization: findings of cross-sectional study in Mosul-Iraq. BMC Pediatr 2014, 14(1):29.

28. Wang Y, Wang Y, Zhang J, Kang C, Duan P: Status of mother's KAP on child immunization in minority areas, Guizhou Province. Beijing Da Xue Xue Bao 2007, 39(2):136-139.

29. Ibnouf $\mathrm{A}$, Van den Borne $\mathrm{H}$, Marse J: Factors influencing immunisation coverage among children under five years of age in Khartoum State, Sudan: original research. S Afr Fam Pract 2007, 49(8):14. 14a-14f.

30. Kim E-Y, Lee M-S: Related factors of age-appropriate immunization among urban-rural children aged 24-35 months in a 2005 population-based survey in Nonsan, Korea. Yonsei Med J 2011, 52(1):104-112.

31. Singh PK: Trends in child immunization across geographical regions in India: focus on urban-rural and gender differentials. PLoS One 2013, 8(9):e73102.

\section{doi:10.1186/1471-2458-14-1107}

Cite this article as: Awadh et al:: Immunization knowledge and practice among Malaysian parents: a questionnaire development and pilot-testing. BMC Public Health 2014 14:1107. 